\title{
INFLUENCE OF MINERAL WATER CONSUMPTION AND RENAL STONE FORMATION
}

\author{
IRSAY Laszlo ${ }^{1,2}$, BORDINC Ecaterina ${ }^{2}$, BORDA Monica ${ }^{1,2}$, UNGUR Rodica ${ }^{1,2}$, \\ CIORTEA Viorela ${ }^{1,2}$, ONAC Ioan ${ }^{1,2}$ \\ ${ }^{1}$ University of Medicine and Pharmacy Cluj-Napoca \\ ${ }^{2}$ Clinical Rehabilitation Hospital Cluj-Napoca
}

\begin{abstract}
The intake of minerals are very important in maintaining health, but in returning to health either. Mineral waters represents a source of minerals with high bioavailability. There are evidence based studies for the efficency of mineral waters in a series of disorders for both internal and external cures. The advantage of mineral waters in renal lithiasis are significant and the risks of stone formation are neglectable if medical advise is respected. Amongst the patients- but unfortunately also the medical staff- there is the incorrect oppinion that mineral water is a factor that causes renal stones in all consumers. The purpose of the present paper is to present the factors that favour the renal stones, but also scientific arguments that support the value of mineral water, that has a part not only in ensuring the right mineral balance but also, in certain situations, even in preventing renal stones.
\end{abstract}

Keywords: renal lithiasis, mineral water consumption, risks of stone formation.

\section{Introduction:}

Nephrolithiasis-from the Greek word nephros, meaning "kidney" and lithos, meaning "stone"-refers to the condition of having stones in the kidney or collecting system. Nephrolithiasis is a world-wide problem, with prevalence rates of 1 to $5 \%$ in Asia, 5 to $9 \%$ in Europe, $13 \%$ in North America, and $20 \%$ in Saudi Arabia. The composition of stones and their location may also significantly differ in different countries. [1].

\section{Epidemiology:}

Nephrolithiasis is a common presentation, with an annual incidence of 7 to 12 cases per 10,000 persons, and a lifetime prevalence of $10 \%$ white men and $5 \%$ women in the United States. Recent studies using the National Health and Nutrition Examination Survey (NHANES) have suggested that the prevalence of stone disease increased from 3.8 to $5.2 \%$ nationwide. This increase was especially observed in whites, in men more than women, and in patients of greater age. When researchers analyzed data from the NHANES, they found the highest incidence of stones to be among Caucasian males (12.8 percent) [1]. Among adults ages 60 and older, 20 percent of men and 10 percent of women had a history of kidney stones [2]. Recent data has suggested that diet and lifestyle may partially account for changes in stonedisease prevalence and for the apparent increase in nephrolithiasis in women. Black women excrete less urinary calcium and have a higher urinary $\mathrm{pH}$ than white women, and therefore have a lower incidence both of nephrolithiasis and of osteoporosis. Rate of recurrence for kidney stones is also much higher in males. The recurrence rate is 10 to $20 \%$ within 1 to 2 years, $35 \%$ within 5 years, and $60 \%$ within 10 years if left untreated. Renal lithiasis can be defined as the consequence of an alteration of the normal crystallization conditions of urine in the urinary tract. In a healthy individual, during the residence time of urine in the urinary tract, crystals either do not form or are so small they are eliminated uneventfully (asymptomatic crystalluria). When normal urine crystallization conditions become altered, however, the rate of crystal nucleation and growth may become such that the crystals 
cannot be easily eliminated due to their size. In some cases, altered urinary conditions affecting crystallization are related to specific underlying disorders such as hyperparathyroidism, which is associated with hypercalciuria, tubular acidosis, which is associated with hypercalciuria and hypocitraturia and some genetic alterations, which are associated with hyperoxaluria, hypercystinuria and hypercalciuria. Indeed, in nearly all renal calculi cases, crystal formation is attributable to a combination of diverse factors that may or may not be associated with an underlying disorder. These factors can be classified into two main groups: urine composition factors and renal morphoanatomy factors. [1,2,3].

Urine is regularly oversaturated with crystals, their presence in urine does not mean stone formation. Oversaturation of urine depends on many factors such as: the amount of liquid ingested and excreted, urine volume, urine $\mathrm{pH}$, urine formation promoters and inhibitors, etc.

Pathogenesis:

There are numerous pathogenic theories such as the precipitation and crystallization theory (the oversaturation theory), the nucleation theory, the suppression of mechanisms of crystallization inhibition, the association of multiple mechanisms.

Studies of the chemical composition of the stones indicated the following incidence: calcium oxalate $(\mathrm{CaOx})$ - the main component $(75-80 \%)$, calcium phosphate $(\mathrm{CaP})-5 \%$, uric acid $5 \%$, struvite - magnesium ammonium phosphate - as a result of infections $\leq 5 \%$, cystine $-1 \%$.

The risk factors for lithogenesis are synthesized in the table below:

\begin{tabular}{|c|c|c|c|}
\hline $\begin{array}{l}\text { Lithogenic } \\
\text { factor }\end{array}$ & Lab value & High risk stones & Diet recommendation \\
\hline $\mathrm{pH}$ & $<5.5$ & $\begin{array}{l}\text { Calcium oxalate, } \\
\text { uric acid, cystine, } \\
\text { mixturres }\end{array}$ & $\begin{array}{l}\text { A lower intake of animal protein } \\
\text { A higher intake of citrus juices and foods rich } \\
\text { in citric acid }\end{array}$ \\
\hline $\mathrm{pH}$ & $>6.0$ & $\begin{array}{l}\text { Calcium oxalate, } \\
\text { hydroxiapatite }\end{array}$ & $\begin{array}{l}\text { A lower intake of vegetal foods, citrus juices, } \\
\text { foods rich in citric acid }\end{array}$ \\
\hline Calcium & $\begin{array}{l}>170 \mathrm{mg} / \mathrm{l} \\
\mathrm{F}>250 \mathrm{mg} / 24 \mathrm{~h} \\
\mathrm{M}>300 \mathrm{mg} / 24 \mathrm{~h}\end{array}$ & $\begin{array}{l}\text { Calcium oxalate, } \\
\text { hydroxiapatite, } \\
\text { mixtures }\end{array}$ & $\begin{array}{l}\text { A lower intake of salt, animal protein } \\
\text { Higher water intake }(>21) \\
\text { Control: the vitamin D intake, the calcium } \\
\text { supplement intake }\end{array}$ \\
\hline Oxalate & $>40 \mathrm{mg} / 24 \mathrm{~h}$ & Calcium oxalate & $\begin{array}{l}\text { A lower intake of foods rich in oxalates and } \\
\text { vitamin } \mathrm{C} \text { (over } 2 \mathrm{~g} / \text { day) }\end{array}$ \\
\hline Citrate & $<350 \mathrm{mg} / 24 \mathrm{~h}$ & $\begin{array}{l}\text { Calcium oxalate, } \\
\text { hydroxiapatite, } \\
\text { mixtures }\end{array}$ & A higher intake of foods rich in citric acid \\
\hline Phytates & $<1 \mathrm{mg} / 24 \mathrm{~h}$ & Calcium oxalate & $\begin{array}{l}\text { A higher intake of foods rich in phytates: } \\
\text { grain (wheat, rice), beans, nuts }\end{array}$ \\
\hline Urates & $\begin{array}{l}>650 \mathrm{mg} / \mathrm{ml} \\
\mathrm{F}>600 \mathrm{mg} / 24 \mathrm{~h} \\
\mathrm{M}>800 \mathrm{mg} / 24 \mathrm{~h}\end{array}$ & $\begin{array}{l}\text { Urates } \\
\text { Calcium oxalate in } \\
\text { mixtures }\end{array}$ & $\begin{array}{l}\text { A lower intake of foods rich in uric acid } \\
\text { (seafood, fish, meat, viscera), alcohol, etc. }\end{array}$ \\
\hline
\end{tabular}


The foods rich in oxalates include spinach, rhubarb, parsley, green/black tea, sprouted wheat, bran, chocolate, peanuts, etc. The same food can have different amounts of oxalates, depending on the cultivation technology, the preparation mode and the intake. [3]

Almost half of the patients suffering from renal lithiasis present with hypercalciuria. This condition varies depending on the gender and age, but it also has a diurnal cycle. There are also seasonal and geographical variations. In women, a significant increase in calciuria occurs after menopause, whereas in men, it occurs in senescence. A decrease in calciuria causes the lithogenesis rate to drop drastically.

There are different types of hypercalciuria:

I. Idiopathic (essential) hypercalciuria

$>$ Absorptive hypercalciuria

$>$ Renal hypercalciuria (the Bartter syndrome, the Dent syndrome)

$>$ Hypophosphatemic hypercalciuria

II. Hypercalciuria secondary to:

$>$ Primary hyperparathyroidism

$>$ Renal distal tubular acidosis

$>$ Immobilization

$>$ Rapidly progressive osteoporosis

$>$ Malignant osteolysis

$>$ Hyperthyroidism

$>$ Paget disease

$>$ Acromegaly

$>$ Hypercortisism (both endogenous and exogenous)

$>$ Sarcoidosis

$>$ Vitamin D overload

III. Hypercalciuria induced by:

$>$ An excessive calcium intake

$>$ An excessive (animal) protein intake

$>$ An excessive salt intake

Other risk factors can be related to the renal anatomy: the presence of cavities (calyces) can cause urinary stasis, alterations of the epithelium that covers the papillae can cause the destruction of the anti-adherent glycosaminoglycan layer, necrosis, subepithelial calcifications, etc.
There are both morphopathological and urine composition factors associated with lithogenesis. The presence of inhibitors is important: only phytates and citrate can be administered through diet or drugs. [3, 4]

A prospective study of more than 45,000 men with a history of kidney stones, found that those with a relatively high dietary intake of calcium (more than $1000 \mathrm{mg} /$ day) actually experienced a 34\% lower incidence of kidney stones compared to those with a relatively low dietary calcium intake. In a 12 year long prospective study of more than 90,000 nurses this same group of researchers found that women who consumed more dietary calcium from food also experienced a reduced risk of developing kidney stones. However, among women who took calcium supplements there was actually about a $20 \%$ increased risk of developing kidney stones. It may be that dietary calcium in whole foods usually reduces oxalate absorption but calcium supplements may not always reduce oxalic acid absorption. Calcium supplements that are not taken with oxalic acid rich foods would not be expected to decrease oxalic acid absorption and excretion. Patients who are prescribed calcium supplements may do better if the supplements are taken in a divided dose with meals. This should reduce oxalic acid absorption.

By contrast, taking a large single dose of calcium before bed may very well increase the risk of calcium-rich kidney stones forming. A supplement of potassium and magnesium citrate may help prevent stone formation when calcium supplements are taken. Calcium citrate is preferable to other calcium supplements.[5,6,7].

Epidemiological studies have shown the negative correlation between the dietary calcium intake and the formation of calcium oxalates, suggesting a protective effect of the former. Excessive calcium excretion is associated with excessive $\mathrm{Na}$ and animal protein intakes. [5, 6, 7] 
Thiazide diuretics cause a decrease in calciuria and are effective in the prevention of lithiasis. [8, 9, 10]

A lower dietary calcium intake is not recommended for patients suffering from renal lithiasis. However, a lower intake of foods rich in oxalates (for example, spinach, rhubarb, parsley, green/black tea, sprouted wheat, bran, chocolate, peanuts and so on) is recommended.

It has been demonstrated that the lowering of the intake of oxalates and ascorbic acid (a precursor to oxalate) only plays a minor role in lithogenesis. The urinary oxalate is a result of the endogenous metabolism of glycoxylate and glycine. [11]

There are no positive associations between renal lithiasis, the intake of fluoridated drinking water and the bone mineral density in women with or without kidney stones. [11]

The fact that the environmental factors (the diet, the intake of water with different concentrations and compositions and so on) are not associated with the process of renal lithogenesis, which is a constant fact, points to the importance of the genetic component within this process. [11]

Bioavailability studies have demonstrated that calcium is better absorbed from mineral water than from milk/dairy products (proven by using radioactive markers on the dietary calcium) or calcium supplements. [12]

All the high-calcium mineral waters had absorbabilities equal to milk calcium or slightly better. When tested, all produced biodynamic responses indicative of absorption of appreciable quantities of calcium (ie, increased urinary calcium, decreased serum parathyroid hormone, decreased bone resorption biomarkers, and protection of bone mass).

High-calcium mineral waters could provide useful quantities of bioavailable calcium. [12]

The magnesium and the bicarbonate ion $(\mathrm{HCO} 3)$ in mineral water act as lithogenesis inhibitors through the following mechanisms: the magnesium reduces the absorption of oxalates at the level of the intestines and therefore their excretion too, whereas the bicarbonate ion can replace urinary alkalinization therapy (using potassium citrate) and lower the level of oxalate saturation (by forming a soluble citrate complex). As far as urinary alkalinization is concerned, the administration of bicarbonate mineral water is equivalent to that of potassium citrate drugs. [13, 14, 15]

Mineral water may or may not bind the oxalates depending on the time of administration. If administered between meals, it does not bind the oxalates in the intestine. If administered during meals, it does bind them and then excretes them through urine. [16]

The research on mineral water and lithogenesis has included comparative studies, randomized studies, double-blind, placebo controlled studies and multicentric studies, all of which have shown that the intake of mineral water rich in calcium bicarbonate is not a factor, regardless of the concentration or the time of administration. [17, 18, 19, 20, 21]

In addition, they have shown that the hardness of the drinking water is in inverse ratio to the risk of kidney stone formation (3.4:3.0) and that bicarbonate water potentiates the effect of the citrate. $[17,18$, $19,20,21]$

Other studies have demonstrated that bicarbonate waters lower the urine $\mathrm{pH}$ levels, increase the excretion of citric acid and lower the excretion of oxalic acid, thus lowering the oversaturation of urine with calcium oxalates and uric acid as well and allowing their use to prevent the formation of oxalate and urate stones. [22, 23, 24]

Romanian balneologists have been constantly showing an interest in the consumption of mineral water as a form of treatment or prevention of renal lithiasis since the 60-70's. Valuable studies have been conducted during this time, some of which meet the current research standards as well. The most frequently studied 
mineral waters include those in Căciulata, Olănesti and other similar resorts. The main results have already been presented. Romanian balneologists often presented their observations and practical contributions with regard to the modifications after 30 days of crenotherapy and not after 3-4 days or one week as recent studies claim. It must be noted that similar studies were conducted in Romania 30-40 years ago. However, neither have they been uploaded on the internet nor translated in a language of international circulation, so the medical world is unaware of their existence and therefore has not taken notice of them. Of course, there are also a number of errors in the work methodology which include the lack of records on the volume of water consumed or the rhythm of administration. $[25,26,27]$

\section{Conclusion:}

Mineral water constitutes an important source of calcium and magnesium, where they are more bioavailable than in supplements or diets. It is not incriminated in lithogenesis if consumed in normal amounts (1.5-2 1/day). As regards concentrated (medicinal) water, the volume must be adjusted according to the patient's particularities (the history of their illness, their personal pathological history, their lab tests, etc.). It has been demonstrated that the local renal factors, also known as morphopathological factors, play an important role in lithogenesis.

Different problems can be encountered when it comes to transposing some studies into practice because we do not know whether the calcium/magnesium/bicarbonate ion ratio varies, if the results are the same (or apply strictly to the waters studied) or if they can be extrapolated.

We are still unaware of the role other ions in the composition of mineral waters play in lithogenesis (even if present only in small amounts), whether they act directly or in combination with other ions or foods: sulfate, iron, chlorine, potassium, etc.

The calcium content of the bottled mineral water available in commerce ranges between 250 and $325 \mathrm{mg} / \mathrm{l}$. The recommended daily intake of calcium and magnesium cannot be reached through rational water consumption even provided that the calcium had an absorbability rate of $100 \%$ per one liter of water. Therefore, lithogenesis through oversaturation is unlikely to occur in the absence of genetic or local affections. 


\section{References:}

1. Zachary Z. Brener, MD, James F. Winchester, MD, Hertzel Salman, MD, Michael Bergman, Nephrolithiasis: Evaluation and Management, South Med J. 2011;104(2):133-139.

2. Charles D. Scales, Jr., Alexandria C. Smith, Janet M. Hanley, Christopher S. Saigal, C.D. Urologic Diseases in America Project-Prevalence of Kidney Stones in the United States- Eur. Urol., July 2012; 62(1): 160-165.

3. Felix Grases, Antonia Costa-Bauza, Rafel M. Prieto- Renal lithiasis and nutrition: Nutrition Journal, September 2006, 5:23, 10.1186/1475-2891-5-23.

4. Fredric L. Coe, Andrew Evan, Elaine Worcester- Kidney stone disease- The Journal of Clinical Investigation http://www.jci.org, Volume 115 Number 10, October 2005, 2598-2604

5. Curhan GC, Willett WC, Rimm EB, Stampher MJ.- A prospective study of dietary calcium and other nutrients and the risk of symptomatic kidney stones.- $\mathrm{N}$ Engl J Med 1993; 328:833-8.

6. Siener R, Ebert D, Nicolay $C$, Hesse A: Dietary risk factors for hyperoxaluria in calcium oxalate stone formers. Kidney Int 2003, 63:1037-1043

7. Taylor EN, Stampfer MJ, Curhan GC: Dietary factors and the risk of incident kidney stones in men: new insights after 14 years of follow-up. J Am Soc Nephrol 2004, 15:32253232.

8. Domrongkitchaiporn $\mathrm{S}$ et al.Schedule of taking calcium supplement and the risk of nephrolithiasis- Kidney Int. 2004 May;65(5):1835-41.

9. Ettinger $B$ et al.-Potassium magnesium citrate is an effective prophylaxis against recurrent calcium oxalate nephrolithiasis- $\mathrm{J}$ Urol 1997;158:2069-73.

10. Coe, F.L et al.- Chlorthalidone promotes mineral retention in patients with idiopathic hypercalciuria-Kidney Int.1988, 33:1140-1146.

11. Sowers MR, Jannausch M, Wood C, Pope SK, Lachance LL, Peterson B.- Prevalence of renal stones in a population-based study with dietary calcium, oxalate, and medication exposures.MRAmerican Journal of Epidemiology, Vol. 147, No. 10, 1998 May 15;147(10):914-20.

12. Robert P Heaney-Absorbability and utility of calcium in mineral watersAm J Clin Nutr 2006;84:371- 4.

13. Liebman M, Costa $G$ : Effects of calcium and magnesium on urinary oxalate excretion after oxalate loads, J. Urol. 2000, 163, 15651569.

14. Nicar MJ, Hill K, Pak CYC: Inhibition by citrate of spontaneous precipitation of calcium oxalate in vitro., J. Bone Miner. Res. 2, 1987, 215-220.

15. Keßler T, Hesse A.: Cross-over study of the influence of bicarbonate-rich mineral water on urinary composition in comparison with sodium potassium citrate in healthy male subjects., Br. J. Nutr. 84, 2000, 865-871.

16. Siener $\mathrm{R}$ et al: Influence of a mineral water rich in calcium, magnesium and bicarbonate on urine composition and the risk of calcium oxalate crystallization., 
European Journal of Clinical Nutrition 2004, 58, 270-276.

17. Shuster J, Finlayson B, Scheaffer R, Sierakowski R, Zoltek J, Dzegede S.- Water hardness and urinary stone disease- J. Urol. 1982 Aug;128(2):422-5.

18. Rodgers AL- Effect of mineral water containing calcium and magnesium on calcium oxalate urolithiasis risk factors- Urol Int.1997;58(2):93-9.

19. Karagülle O, Smorag U, Candir F, Gundermann G, Jonas U, Becker AJ, Gehrke A, Gutenbrunner C.Clinical study on the effect of mineral waters containing bicarbonate on the risk of urinary stone formation in patients with multiple episodes of $\mathrm{CaOx}-$ urolithiasis- World J. Urol., 2007 Jun;25(3):315-23.

20. Siener R, Jahnen A, Hesse AInfluence of a mineral water rich in calcium, magnesium and bicarbonate on urine composition and the risk of calcium oxalate crystallization- Eur J Clin Nutr., 2004 Feb; 58(2):270-6.

21. Schwartz BF, Schenkman NS, Bruce JE, Leslie SW, Stoller MLCalcium nephrolithiasis: effect of water hardness on urinary electrolytes- Urology., 2002 Jul;60(1):23-7.

22. Kessler T, Hesse A.- Cross-over study of the influence of bicarbonate-rich mineral water on urinary composition in comparison with sodium potassium citrate in healthy male subjects.-Br J Nutr, 2000 Dec; 84(6): 865-7.

23. Shuster J, Finlayson B, Scheaffer RL, Sierakowski R, Zoltek J, Dzegede S.- Primary liquid intake and urinary stone disease.- $\mathbf{J}$ Chronic Dis, 1985;38(11):907-14.

24. Caudarella R, Rizzoli E, Buffa A, Bottura A, Stefoni S.- Comparative study of the influence of 3 types of mineral water in patients with idiopathic calcium lithiasis.- J Urol, 1998 Mar; 159(3):658-63.

25. Burghele Th., Dinculescu Tr., Covaliu T, Cociasu E. et al.Efectul apelor de Caciulata in cadrul tratamentului conservator al litiazei urinare- Studii si cercetari de balneologie si fizioterapie, vol VII, Edit Medicala Bucure $\square$ ti, 1967, 522-532

26. Burghele Th., Dinculescu Tr., Covaliu T., Reugendorff E. et al.Evolutia indicilor de homeostazie ionica in sange si a eliminarilor urinare la bolnavii cu litiaza de tip calcic cu apa de Caciulata si tratament medicamentos- Studii si cercetari de balneologie si fizioterapie, vol IX, Edit Medicala Bucure $\square$ ti, 1967, 303-315

27. Burghele Th., Dinculescu Tr., Cociasu E. Et al: Efectul apelor minerale în tratamentul litiazei renale. Studii si cercetari de balneologie si fizioterapie, vol VII, Edit Medicala Bucure $\square$ ti, 1965, 299-305 